\title{
Long-term patency in cerebral revascularization surgery: an analysis of a consecutive series of $\mathbf{4 3 0}$ bypasses
}

\author{
Seungwon Yoon, BS, ${ }^{1}$ Jan-Karl Burkhardt, MD, ${ }^{2}$ and Michael T. Lawton, MD${ }^{1}$ \\ 'Department of Neurological Surgery, Barrow Neurological Institute, Phoenix, Arizona; and 'Department of Neurological Surgery, \\ University of California, San Francisco, California
}

\begin{abstract}
OBJECTIVE Large cohort analysis concerning intracerebral bypass patency in patients with long-term follow-up (FU) results is rarely reported in the literature. The authors analyzed the long-term patency of extracranial-to-intracranial (ECIC) and intracranial-to-intracranial (IC-IC) bypass procedures.
\end{abstract}

METHODS All intracranial bypass procedures performed between 1997 and 2017 by a single surgeon were screened. Patients with postoperative imaging (CT angiography, MR angiography, or catheter angiography) were included and grouped into immediate (< 7 days), short-term ( 7 days -1 year), and long-term ( $>1$ year) FU groups. Data on patient demographics, bypass type, interposition graft type, bypass indication, and radiological patency were collected and analyzed with univariate and multivariate (adjusted multiple regression) models.

RESULTS In total, 430 consecutive bypass procedures were performed during the study period (FU time [mean \pm SD] $0.9 \pm 2.2$ years, range $0-17$ years). Twelve cases were occluded at FU imaging, resulting in an overall cumulative patency rate of $97 \%$. All bypass occlusions occurred within a week of revascularization. All patients in the short-term FU group ( $n=76$, mean FU time $0.3 \pm 0.3$ years) and long-term FU group ( $n=89$, mean FU time $4.1 \pm 3.5$ years) had patent bypasses at last FU. Patients who presented with aneurysms had a lower rate of patency than those with moyamoya disease or chronic vessel occlusion $(p=0.029)$. Low-flow bypasses had a significantly higher patency rate than high-flow bypasses $(p=0.033)$. In addition, bypasses with one anastomosis site compared to two anastomosis sites showed a significantly higher bypass patency $(p=0.005)$. No differences were seen in the patency rate among different grafts, single versus bilateral, or between EC-IC and IC-IC bypasses.

CONCLUSIONS The overall bypass patency of $97 \%$ indicates a high likelihood of success with microsurgical revascularization. Surgical indication (ischemia), low-flow bypass, and number of anastomosis (one site) were associated with higher patency rates. EC-IC and IC-IC bypasses have comparable patency rates, supporting the use of intracranial reconstructive techniques. Bypasses that remain patent 1 week postoperatively and have the opportunity to mature have a high likelihood of remaining patent in the long term. In experienced hands, cerebral revascularization is a durable treatment option with high patency rates.

https://thejns.org/doi/abs/10.3171/2018.3.JNS172158

KEYWORDS cerebral revascularization; bypass surgery; anastomosis; vascular neurosurgery; bypass patency; vascular disorders

$\mathrm{B}$ YPASS surgery is a highly technical procedure performed to prevent ischemic complications in patients with various cerebrovascular diseases. ${ }^{13,20}$ Indications for bypass surgery include arterial stenosis or occlusion, secondary cerebral ischemia, complex aneurysms that cannot be treated by endovascular procedures or conventional clipping, and skull base tumors that encase the carotid artery. $2,7-12,17,19,23$ The spectrum of revascularization procedures is broad. Selection of a bypass procedure depends on flow requirements of the bypass, the anatomy of the vessels associated with the underlying pathology, and the presence of neurological deficits. ${ }^{9,18}$ In these pro-

ABBREVIATIONS ACA = anterior cerebral artery; EC = extracranial; FU = follow-up; IC = intracranial; ICA = internal carotid artery; $M C A=$ middle cerebral artery; PCA = posterior cerebral artery; PICA = posterior inferior cerebellar artery; RAG = radial artery graft; SCA = superior cerebellar artery; STA = superficial temporal artery. SUBMITTED August 29, 2017. ACCEPTED March 6, 2018.

INCLUDE WHEN CITING Published online August 24, 2018; DOI: 10.3171/2018.3.JNS172158. 
cedures, the patency of the bypass is a key determinant of the success of the intervention and the long-term survival of the patient. ${ }^{16}$

Despite increases in the safety and feasibility of bypass procedures and advances in surgical techniques and neuroanesthesia,${ }^{21}$ there is a paucity of large patient cohort analyses on cerebral bypass patency reported in the literature with long-term follow-up (FU) results. In a 1995 study conducted at the Mayo Clinic, the authors found the cumulative patency of long saphenous vein grafts between extracranial (EC) and intracranial (IC) circulation among 202 patients to be $86 \%, 82 \%$, and $73 \%$ at 1,5 , and 13 years, respectively. ${ }^{16}$ In a study published by the EC/ IC Bypass Study Group in 1985, the postoperative bypass patency rate was $96 \%$ among the 652 patients who underwent anastomosis of the superficial temporal artery (STA) to the middle cerebral artery (MCA), with the longest FU of 7.5 years. ${ }^{6}$ We have accumulated a large experience with cerebral revascularization and wanted to document our patency data in the literature. This study analyzes the long-term patency of 430 consecutive EC-IC and IC-IC bypass procedures performed over 20 years.

\section{Methods}

This study was approved by the IRB and conducted in compliance with Health Insurance Portability and Accountability Act regulations. The inclusion criterion for the present study was all patients who underwent cerebral revascularization performed by a single attending (M.T.L.) between November 1997 and May 2017. For each case, we extracted the following patient demographic and clinical data from our electronic medical record system (APeX, EPIC Inc.): patient age, sex, diagnosis, principal procedure, and types of bypasses. We then performed a manual chart review to collect data on imaging studies, through either a catheter-based digital subtraction angiogram, computed tomography angiogram, or magnetic resonance angiogram, completed at preoperation, postoperation, and FU. Bypass patency was determined first by assessment of radiological imaging reports by independent radiologists, then confirmed by manual review of all images by a radiology-trained neurosurgeon (J.K.B.).

Long-term patency was compared among different techniques. Bypass techniques for various intracranial arteries and indications (complex aneurysms, moyamoya disease, and occlusions) were categorized into high-flow and low-flow bypasses as well as EC-IC, or IC-IC anastomosis, as described previously. ${ }^{14}$ Additionally, we differentiated between bypasses with or without an interposition graft, such as a saphenous vein or a radial artery. In a subset analysis of IC-IC bypasses for aneurysm treatment, cases were grouped into (1) with the use of an interposition graft, (2) with in situ anastomosis, (3) with aneurysm trapping and vessel reimplantation, and (4) with aneurysm excision and reanastomosis.

Data aggregation and exploratory analysis were performed in Microsoft Excel (version 16, Microsoft Corp.). The statistical program Stata/SE 15 (Stata Corporation) was used to perform chi-square tests and Fisher's exact test for categorical variables with small cell counts. The prima- ry outcome analyzed was the patency of the bypass. Kaplan-Meier analysis was performed to illustrate cumulative patency with occluded bypass as the event of interest. Since surgeon experience can be an important confounding variable in bypass patency, we created an adjusted multiple logistic regression model with the log of surgeon experience years. All values are expressed as average \pm standard deviation, where appropriate, and statistical significance was established at the alpha level of $\mathrm{p}=0.05$.

\section{Results}

\section{Patient and Revascularization Characteristics}

Four hundred and thirty consecutive bypass surgery procedures were performed between 1997 and 2017 (Table 1). The average age of patients was $47.8(\mathrm{SD} \pm 19.9)$ years, and $59 \%(\mathrm{n}=255)$ were female. Surgical indications for bypass revascularization were complex aneurysm $(\mathrm{n}=175 ; 41 \%)$, moyamoya disease $(\mathrm{n}=132 ; 31 \%)$, arterial stenosis or occlusion $(n=120 ; 28 \%)$, cancer $(n=2 ;<1 \%)$, and arteriovenous malformation $(\mathrm{n}=1 ;<1 \%)$. There were 361 EC-IC bypasses, with STA-MCA bypasses comprising the majority of these cases $(n=261)$, and 67 IC-IC bypasses performed. The mean FU time, calculated as the number of years between the initial procedure and the latest imaging study that confirmed patency, was $0.9 \pm 2.2$ years.

\section{Follow-Up Results}

Of the 430 cerebral revascularization procedures in the series, 12 were occluded at FU imaging, resulting in an overall cumulative patency rate of $97 \%$ (Fig. 1). We categorized the patients into 3 groups based on the FU time: 265 immediate ( $<7$ days) FU patients, 76 short-term $(>7$ days, $<1$ year) FU patients, and 89 long-term $(>1$ year) FU patients. All 12 cases of a nonpatent bypass were in the immediate FU group, which resulted in a 95\% patency rate in this cohort. All patients in the short-term FU group had a patent bypass, with an average FU time for this group of $0.3 \pm 0.3$ years. In 89 of the 430 cases, longterm patency could be assessed with an average FU time of 4.1 years \pm 3.5 years (range $1-17$ years). There were no cases of bypass occlusion, and 14 patients were followed for over 8 years. A case example of a high-flow bypass at the 5-year postoperative FU is illustrated in Fig. 2.

\section{Risk Factors for Bypass Occlusion}

We observed a statistically significant difference in the patency rates based on the preoperative diagnosis (Table 2). Patients who presented with an aneurysm had a lower rate of bypass patency than those who presented with moyamoya disease or occlusion $(p=0.029)$. This effect persisted among the 262 patients in the immediate FU group $(\mathrm{p}=0.048)$. For patients who were treated with an IC-IC bypass procedure for a complex aneurysm $(n=66)$, there was no significant patency difference between the 4 bypass groups: 1) with the use of an interposition graft, 2) with an in situ anastomosis, 3) with aneurysm trapping and vessel reimplantation, and 4) with aneurysm excision and reanastomosis $(\mathrm{p}=0.289)$.

Patients who underwent bypass with two anastomosis 
TABLE 1. Patient demographics and clinical characteristics of bypass procedures between 1997 and 2017

\begin{tabular}{|c|c|}
\hline Variable & No. $(\%)$ \\
\hline No. of bypasses & 430 \\
\hline Age, yrs & $47.8 \pm 19.9$ \\
\hline \multicolumn{2}{|l|}{ Sex } \\
\hline Male & $175(40.7)$ \\
\hline Female & $255(59.3)$ \\
\hline \multicolumn{2}{|l|}{ FU time } \\
\hline Immediate (<1 wk) & $265(61.6)$ \\
\hline Short term (1 wk-1 yr) & $76(17.7)$ \\
\hline Long term (>1 yr) & $89(20.7)$ \\
\hline \multicolumn{2}{|l|}{ Diagnosis } \\
\hline Aneurysm & $175(40.7)$ \\
\hline Moyamoya disease & $132(30.7)$ \\
\hline Occlusion & $120(27.9)$ \\
\hline Others (cancer, AVM) & $3(0.7)$ \\
\hline \multicolumn{2}{|l|}{ No. of anastomosis sites } \\
\hline 1 & $349(81.2)$ \\
\hline 2 & $81(18.8)$ \\
\hline \multicolumn{2}{|l|}{ Graft type } \\
\hline Radial artery & $36(8.4)$ \\
\hline Saphenous vein & $44(10.2)$ \\
\hline IC-IC w/o interposition & $65(15.1)$ \\
\hline None & $285(66.3)$ \\
\hline \multicolumn{2}{|l|}{ Bypass type } \\
\hline High-flow EC-EC & $66(15.3)$ \\
\hline Low-flow EC-EC & $295(68.6)$ \\
\hline High-flow IC-IC & $12(2.8)$ \\
\hline Low-flow IC-IC & $55(12.8)$ \\
\hline \multicolumn{2}{|l|}{ No. of bypasses } \\
\hline Single & $377(87.7)$ \\
\hline Double & $53(12.3)$ \\
\hline
\end{tabular}

$\mathrm{AVM}=$ arteriovenous malformation.

Values are expressed as the number (\%) of operations or the mean \pm SD, where appropriate.

sites (interposition grafts and end-to-end or end-to-side anastomosis) had a higher risk of bypass occlusion than those who received a bypass with one anastomosis site (end-to-side anastomosis, and excision and end-to-end or end-to-side anastomosis) (93\% vs 98\%, $\mathrm{p}=0.005$; Table 2). Furthermore, we found that patients with a high-flow bypass had a higher risk of bypass occlusion than patients with low-flow bypass ( $94 \%$ vs $98 \%, \mathrm{p}=0.033$; Table $2)$. Both of these effects were present in the immediate FU group $(\mathrm{p}<0.01)$. When comparing the patency rate among 145 bypass procedures that used a radial artery graft (RAG), a saphenous vein graft, or an IC-IC without an interposition graft, there was no statistically significant difference in the patency rate among these groups $(\mathrm{p}=$ 0.899; Table 2).

Lastly, we created an adjusted multiple logistic regres-

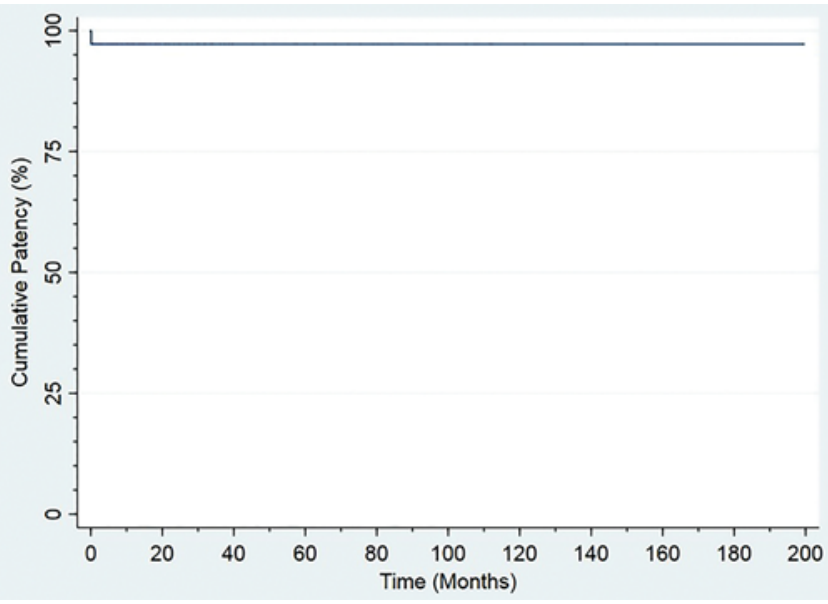

FIG. 1. Cumulative patency of 430 cases of cerebral revascularization over 20 years.

sion model with bypass patency as the primary outcome to account for the increase in the surgeon's years of experience for more recent patients in our cohort (Table 3). The adjusted model confirmed number of anastomosis sites and flow as independent predictors of bypass patency ( $p$ $=0.008$ and 0.039 , respectively). There was no significant difference in patency rate between EC-IC bypasses and IC-IC bypasses $(\mathrm{p}=0.377)$.

\section{Occluded Bypasses}

There were 12 cases of occluded bypasses, all detected early within the 1st week of surgery (Table 4). The average age was $47.5 \pm 15.6$ years, and 8 patients were female. The majority of these patients presented with complex, giant aneurysms that failed conventional clipping (Fig. $3)$. Six of the occluded bypass patients received an interposition graft ( 2 radial arteries and 4 saphenous veins). One patient underwent bilateral STA-MCA bypass procedures, and only the right bypass was occluded. Seven patients suffered a postoperative stroke with new or worsening neurological deficits, and one patient experienced decreased cranial nerve III and IV function. Four of the occluded bypasses - in the 3 moymoya patients and in 1 mycotic aneurysm patient with distal anastomosis of the posterior cerebral artery (PCA)-were clinically asymptomatic. Only one patient received surgery after occlusion (indirect revascularization), which formed new anastomotic flow at last FU.

\section{Discussion}

Our cohort analysis of 430 bypass procedures shows that the overall patency rate was over $97 \%$. All occlusions of bypasses took place within the 1st week of surgery and were included in the immediate FU group. Bypass occlusion did not correlate with patient age or sex. Interestingly, our data show that there was no statistically significant difference in patency rate among patients with the use of a RAG, saphenous vein graft, and in situ bypass ( $p=0.899$; Table 2). In their randomized control trial, Desai et al. 

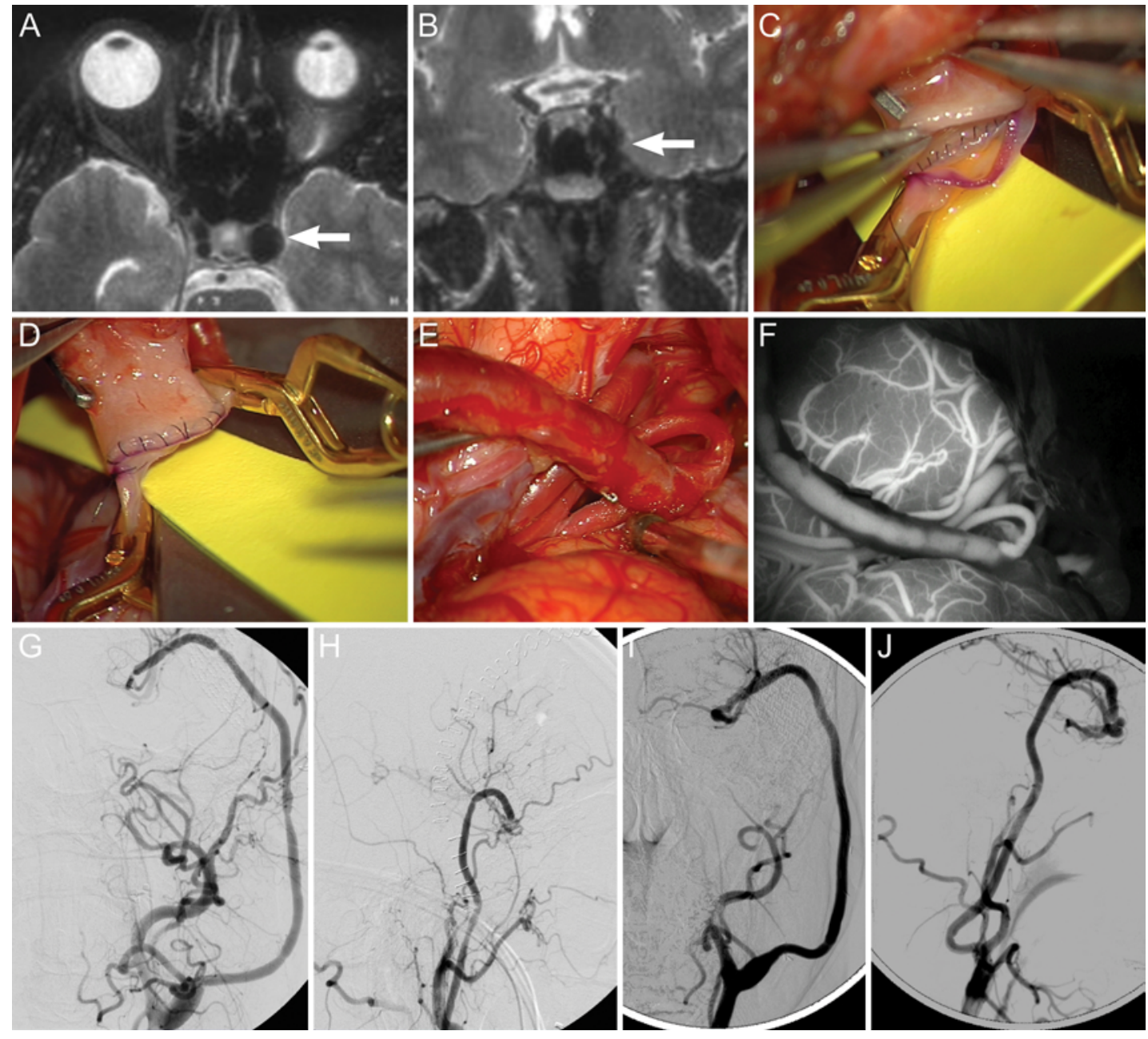

FIG. 2. This 40-year-old man presented with a left cranial nerve VI palsy due to compression from a left fusiform ICA aneurysm

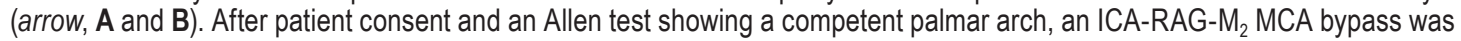
performed through a left pterional craniotomy. The MCA was brought into full view with a wide Sylvian fissure split, and the frontal trunk of the MCA bifurcation was selected for the bypass after the RAG was harvested from the left forearm. Temporary clips were placed on the recipient MCA after first placing the patient in barbiturate-induced electroencephalogram burst suppression, and the anastomosis was completed with running 9-0 monofilament nylon sutures. The first suture line was inspected intraluminally (C) and the second suture line was then sewn in similar fashion (D). The proximal end-to-end anastomosis was completed to the cervical ICA and flow was initiated in the bypass (E). There was good pulsation in the graft, and an indocyanine green angiogram confirmed patency $(F)$. Postoperative angiography showed patency of the bypass with filling of the MCA territory through the bypass and occlusion of the ICA aneurysm (left ICA angiogram, anteroposterior [G] and lateral $[\mathrm{H}]$ views). The patient recovered well from surgery with no neurological deficits. Five-year FU catheter angiography confirmed patency of the bypass (left ICA angiogram, anteroposterior [I] and lateral [J] views). This case demonstrates maturation of a high-flow bypass at late FU.

found that the RAGs had a higher rate of patency at 1 year than saphenous vein grafts. ${ }^{5}$ Although we did not observe such a difference in patency rates between patients who received a RAG and those treated with a saphenous vein graft (odds ratio 0.835; $\mathrm{p}=0.866$; Table 3 ), a $\mathrm{RAG}$ is preferred over a saphenous vein graft in our practice. Despite similar patency rates among the different grafts, we believe the RAG resembles the arterial vessel characteristics of an intracranial recipient artery substantially more than a saphenous vein graft. However, if a RAG is not available (for example, the patient fails the Allen test), the saphenous vein is used as an alternative.

In our analysis, bypass procedures with one anasto- mosis site had a higher rate of patency compared to two anastomosis sites $(\mathrm{p}=0.005$; Table 2$)$. Furthermore, patients who underwent low-flow bypass procedures had a higher rate of patency than those who underwent highflow bypass procedures ( $p=0.033$; Table 3 ). This is likely because the low-flow bypasses, especially in patients with moyamoya disease or internal carotid artery (ICA) occlusion, have high demand on them to augment blood flow, which encourages bypass patency. In high-flow bypasses, there are more confounding factors that impact bypass patency, such as an increase in the number of anastomosis sites and the restoration, rather than augmentation, of blood flow. 
TABLE 2. Univariate analysis of predictors of bypass patency stratified by length of FU

\begin{tabular}{|c|c|c|c|c|}
\hline Factor & Overall Patency & Immediate FU & Short-Term FU & Long-Term FU \\
\hline \multicolumn{5}{|l|}{ Diagnosis* } \\
\hline Aneurysm & $95 \%(9 / 175)$ & $93 \%(9 / 125)$ & $100 \%(0 / 22)$ & $100 \%(0 / 28)$ \\
\hline Moyamoya & $98 \%(3 / 132)$ & $95 \%(3 / 57)$ & $100 \%(0 / 37)$ & $100 \%(0 / 38)$ \\
\hline Occlusion & $100 \%(0 / 120)$ & $100 \%(0 / 83)$ & $100 \%(0 / 14)$ & $100 \%(0 / 23)$ \\
\hline$p$ value & 0.029 & 0.048 & 1.000 & 1.000 \\
\hline \multicolumn{5}{|l|}{ No. of anastomosis sites } \\
\hline 1 & $98 \%(6 / 349)$ & $97 \%(6 / 207)$ & $100 \%(0 / 70)$ & $100 \%(0 / 72)$ \\
\hline 2 & $93 \%(6 / 81)$ & $90 \%(6 / 58)$ & $100 \%(0 / 6)$ & $100 \%(0 / 17)$ \\
\hline$p$ value & 0.005 & 0.016 & 1.000 & 1.000 \\
\hline \multicolumn{5}{|l|}{ Flow } \\
\hline High & $94 \%(5 / 78)$ & $91 \%(5 / 55)$ & $100 \%(0 / 6)$ & $100 \%(0 / 17)$ \\
\hline Low & $98 \%(7 / 350)$ & $97 \%(7 / 208)$ & $100 \%(0 / 70)$ & $97 \%(0 / 72)$ \\
\hline$p$ value & 0.033 & 0.070 & 1.000 & 1.000 \\
\hline \multicolumn{5}{|l|}{ Bypass type } \\
\hline EC-IC & $98 \%(9 / 361)$ & $96 \%(9 / 214)$ & $100 \%(0 / 63)$ & $100 \%(0 / 84)$ \\
\hline IC-IC & $96 \%(3 / 67)$ & $94 \%(3 / 49)$ & $100 \%(0 / 13)$ & $100 \%(0 / 5)$ \\
\hline$p$ value & 0.366 & 0.562 & 1.000 & 1.000 \\
\hline \multicolumn{5}{|l|}{ Grafts } \\
\hline Radial artery & $94 \%(2 / 36)$ & $92 \%(2 / 25)$ & $100 \%(0 / 2)$ & $100 \%(0 / 9)$ \\
\hline Saphenous vein & $93 \%(3 / 44)$ & $91 \%(3 / 33)$ & $100 \%(0 / 4)$ & $100 \%(0 / 7)$ \\
\hline IC-IC w/o interposition & $95 \%(3 / 65)$ & $96 \%(3 / 46)$ & $100 \%(0 / 14)$ & $100 \%(0 / 5)$ \\
\hline$p$ value & 0.885 & 0.690 & 1.000 & 1.000 \\
\hline \multicolumn{5}{|l|}{ No. of bypasses } \\
\hline Single & $98 \%(9 / 377)$ & $96 \%(9 / 232)$ & $100 \%(0 / 69)$ & $100 \%(0 / 76)$ \\
\hline Double & $94 \%(3 / 53)$ & $91 \%(3 / 33)$ & $100 \%(0 / 7)$ & $100 \%(0 / 13)$ \\
\hline$p$ value & 0.176 & 0.178 & 1.000 & 1.000 \\
\hline
\end{tabular}

Values are expressed as percentage of patent bypasses (number of occluded bypasses/total number of bypasses). Boldface indicates statistical significance $(p<0.05)$.

* Patients with a diagnosis of cancer and arteriovenous malformation were excluded due to the low frequency of these diagnoses in these groups $(n=3)$.

In 12 patients with an occluded bypass on FU imaging, demographic characteristics were similar to those of the overall cohort. Nine patients presented with a complex aneurysm, and 3 patients presented with moyamoya disease. While the difference in patency rate was not statistically significant, the lower rate of bypass occlusion that we observed in patients with moyamoya disease or occlusive cerebrovascular disease could be explained by the bypass demand: revascularization will augment flow in occluded regions of the brain. Bypass procedures with increased cerebrovascular flow are more likely to keep the bypass open than are procedures performed to preserve the flow, such as in complex aneurysm treatments. ${ }^{3}$

Our patient series covers surgical treatment of complex aneurysms over 20 years, including high-flow EC-IC bypasses for complex ICA aneurysms before the introduction of flow diversion. The recently published promising results with the Pipeline Embolization Device to treat fusiform or wide-neck ICA aneurysms will decrease the frequency of EC-IC bypasses in the future, ${ }^{4}$ but bypass will always remain a treatment alternative for failed Pipeline cases. In our cohort, there were 27 cases of bypasses for complex aneurysms prior to 2008, when Pipeline emboli-
TABLE 3. Adjusted multiple regression model of predictors of bypass patency

\begin{tabular}{lccc}
\hline \multicolumn{1}{c}{ Factor } & $\begin{array}{c}\text { Odds } \\
\text { Ratio }\end{array}$ & $\begin{array}{c}95 \% \\
\mathrm{Cl}\end{array}$ & $\begin{array}{c}\mathrm{p} \\
\text { Value }\end{array}$ \\
\hline Diagnosis (vs aneurysm) & & & \\
\hline \multicolumn{1}{c}{ Moyamoya disease } & 2.446 & $(0.639-9.37)$ & 0.192 \\
\hline Occlusion & 1.000 & $\mathrm{NA}$ & $\mathrm{NA}$ \\
\hline No. of anastomosis sites (1 vs 2) & 0.206 & $(0.064-0.667)$ & $\mathbf{0 . 0 0 8}$ \\
\hline Flow (high vs low) & 3.482 & $(1.065-11.381)$ & 0.039 \\
\hline Bypass type (EC-IC vs IC-IC) & 0.548 & $(0.144-2.080)$ & 0.377 \\
\hline Grafts (vs radial artery) & & & \\
\hline \multicolumn{1}{c}{ Saphenous vein } & 0.835 & $(0.103-6.788)$ & 0.866 \\
\hline IC-IC w/o interposition & 1.227 & $(0.192-7.827)$ & 0.829 \\
\hline No. of bypasses (single vs double) & 0.413 & $(0.105-1.623)$ & 0.206 \\
\hline Logtime of surgeon experience & 0.426 & $(0.031-5.885)$ & 0.524 \\
\hline
\end{tabular}

$\mathrm{NA}=$ not applicable.

Boldface indicates statistical significance $(p<0.05)$. 
TABLE 4. Clinical characteristics of 12 occluded bypasses

\begin{tabular}{|c|c|c|c|c|c|c|c|c|c|c|}
\hline $\begin{array}{l}\text { Case } \\
\text { No. }\end{array}$ & $\begin{array}{l}\text { Age } \\
\text { (yrs) }\end{array}$ & Sex & Year & Diagnosis & Bypasses & Bypass Type & Graft & $\begin{array}{l}\text { Time of } \\
\text { Occlusion }\end{array}$ & Clinical Relevance & Reop \\
\hline 1 & 61 & $\mathrm{~F}$ & 2000 & Aneurysm & ECA-SVG-MCA & EC-IC, high flow & $\begin{array}{l}\text { Saphenous } \\
\text { vein }\end{array}$ & 1 day & Stroke; more/new deficits & No \\
\hline 2 & 24 & $F$ & 2002 & Aneurysm & $\begin{array}{r}\text { Petrous ICA-SVG- } \\
\text { supraclinoid ICA }\end{array}$ & IC-IC, high flow & $\begin{array}{l}\text { Saphenous } \\
\text { vein }\end{array}$ & 1 day & $\begin{array}{l}\text { Decline; decreased It CN } \\
\quad \text { III \& IV function }\end{array}$ & No \\
\hline 3 & 41 & $\mathrm{~F}$ & 2005 & Aneurysm & $\begin{array}{r}\text { Cervical ICA- } \\
\text { RAG-MCA }\end{array}$ & EC-IC, high flow & Radial artery & 2 days & Stroke; more/new deficits & No \\
\hline 4 & 63 & $\mathrm{~F}$ & 2007 & Aneurysm & MCA-MCA & IC-IC, low flow & $\begin{array}{l}\text { In situ anas- } \\
\text { tomosis }\end{array}$ & $\begin{array}{l}\text { Immediately } \\
\text { postop }\end{array}$ & Stroke; more/new deficits & No \\
\hline 5 & 66 & $\mathrm{~F}$ & 2007 & Aneurysm & ECA-SVG-MCA & EC-IC, high flow & $\begin{array}{l}\text { Saphenous } \\
\text { vein }\end{array}$ & 1 day & Stroke; more/new deficits & No \\
\hline 6 & 57 & $\mathrm{~F}$ & 2007 & Aneurysm & ATA-SVG-ACA & IC-IC, low flow & $\begin{array}{l}\text { Saphenous } \\
\text { vein }\end{array}$ & 1 day & Stroke; more/new deficits & No \\
\hline 7 & 43 & M & 2010 & Moyamoya & STA-MCA & EC-IC, low flow & & 5 days & Silent & No \\
\hline 8 & 47 & $\mathrm{~F}$ & 2010 & Moyamoya & $\begin{array}{l}\text { STA-MCA (It); STA- } \\
\quad \text { MCA (rt) }\end{array}$ & EC-IC, low flow & & $\begin{array}{r}\text { Immediately } \\
\text { postop (rt } \\
\text { side only) }\end{array}$ & Silent & Yes; onlay \\
\hline 9 & 42 & M & 2014 & Aneurysm & $\begin{array}{l}\text { VA-AICA; AICA- } \\
\quad \text { AICA }\end{array}$ & IC-IC, low flow & & 1 day & Stroke; more/new deficits & No \\
\hline 10 & 67 & $\mathrm{~F}$ & 2015 & Aneurysm & ECA-RAG-MCA & EC-IC, high flow & Radial artery & 1 day & Stroke; more/new deficits & No \\
\hline 11 & 38 & $M$ & 2015 & Moyamoya & STA-MCA & EC-IC, low flow & & 1 day & Silent & No \\
\hline 12 & 21 & $\mathrm{~F}$ & 2017 & Aneurysm & $\begin{array}{l}\text { PCA excision/re- } \\
\text { anastomosis }\end{array}$ & IC-IC, low flow & & 1 day & Silent & No \\
\hline
\end{tabular}

$\mathrm{AICA}=$ anterior inferior cerebellar artery; $\mathrm{CN}$ = cranial nerve; $\mathrm{ECA}$ = external carotid artery; $\mathrm{SVG}$ = saphenous vein graft; $\mathrm{VA}$ = vertebral artery.

zation became available in the US, and 39 cases performed after 2008, suggesting that direct revascularization is still an important treatment option. In addition, fusiform aneurysms in vessels with smaller diameters, such as in the posterior inferior cerebellar artery (PICA), MCA, or anterior cerebral artery (ACA) territories, and aneurysms with complex branching vessels will remain challenging for flow diversion or other endovascular treatment methods and will continue to require bypasses as part of a curative treatment strategy without aneurysm residual or arterial deconstruction.

All bypass occlusions occurred within a week of revascularization, with 2 of the occlusions occurring immediately after the operation. Eight patients with an occluded bypass suffered a stroke or worsening neurological deficits, while the occlusion was clinically silent in 4 patients. The long-term patency of the bypass procedures seems to be excellent, as none of the 165 patients with greater than 1 week of FU developed an occlusion; all of the 24 patients with an FU of over 5 years had patent bypasses. Therefore, bypasses that remain patent within a week of the postoperative period and that have the opportunity to mature have a high likelihood of remaining patent long term. Further radiological imaging may be unnecessary for asymptomatic patients whose bypass was patent at 1 week postoperatively. In our system of rising healthcare costs, reduction in the frequency of FU imaging studies, supported by clinical evidence, may help deliver sustainable, cost-effective healthcare.
The major limitation of our study is the single-site, single-surgeon nature of the project. However, these factors eliminate variations in technique that may be introduced by a multicenter study with multiple surgeons. Our study did not analyze clinical outcomes or survival rate of patients, as the study focused narrowly on bypass patency, and clinical outcomes have been published in other reports from our group. . $15,18,22$ Additionally, other factors contributing to bypass occlusion, including caliber vessel mismatches, weak bypass indications, and technical errors, should be kept in mind. While the cases at our tertiary referral center may not be representative of the neurosurgical cases nationally, this review from our series of 430 bypass procedures performed over the course of 20 years provides insights on the natural history and long-term durability of bypass procedures and specifically documents long-term patency results in a sizable cohort of IC-IC bypass patients.

\section{Conclusions}

The overall bypass patency rate in this cohort was over $97 \%$, indicating a high likelihood of success with microsurgical revascularization. Surgical indication (ischemia), low flow, and number of anastomoses (one site) were factors associated with higher patency rates. IC-IC bypasses have patency rates comparable to EC-IC bypasses, supporting the use of these reconstructive techniques. Bypasses that remain patent in the immediate postoperative period and 

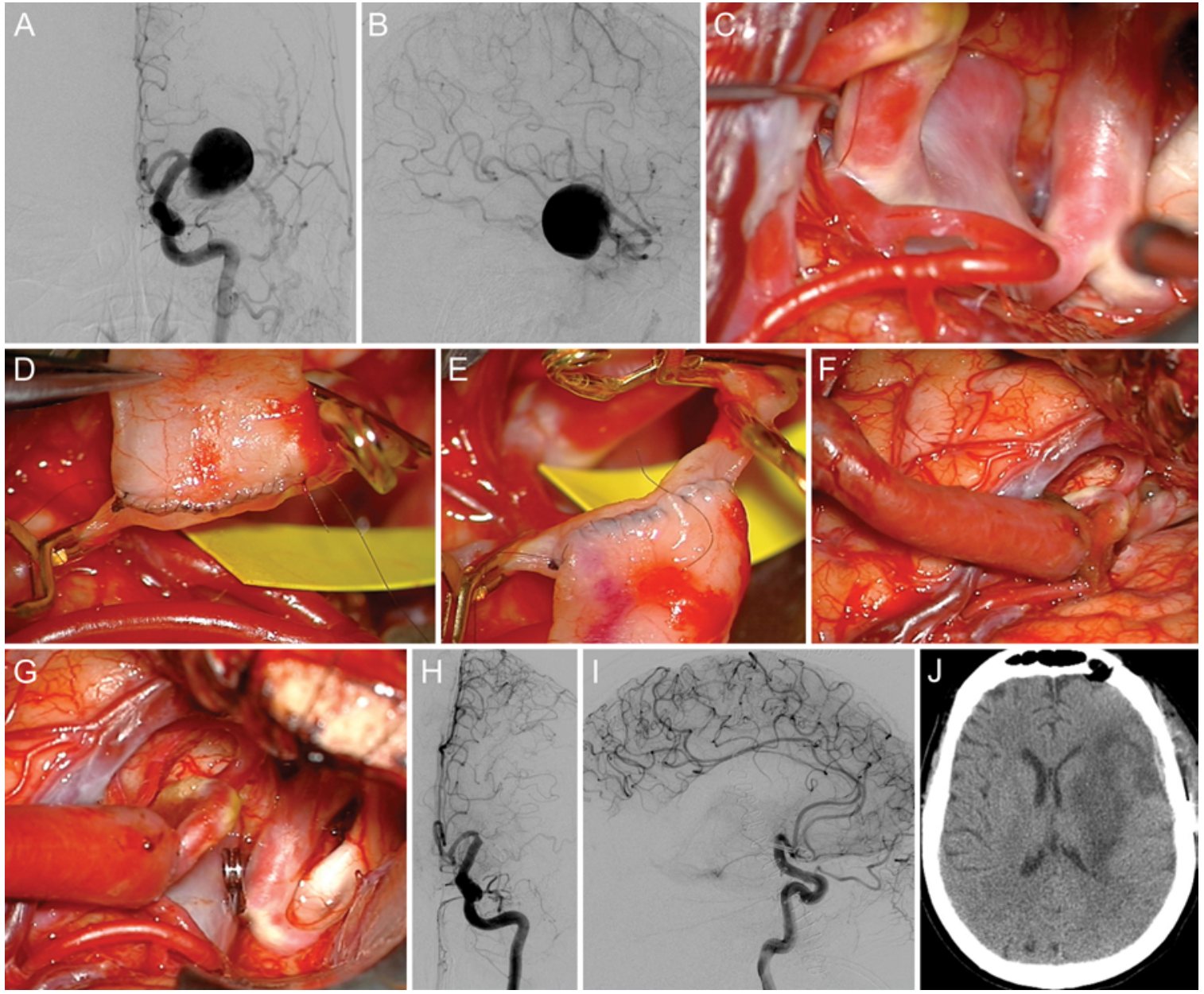

FIG. 3. This 66-year-old woman presented with seizures due to a giant left $\mathrm{M}_{1}$ aneurysm (left ICA angiogram, anteroposterior [A] and lateral [B] views). After patient consent and a failed Allen test, a left external carotid artery-saphenous vein graft- $\mathrm{M}_{2}$ segment bypass was performed through a pterional craniotomy. The MCA aneurysm was in full view after a wide Sylvian fissure split, and a $\mathrm{M}_{2}$ branch was selected for the bypass (C). The saphenous vein was harvested from her leg and had significant varicosities. The first suture line was completed with running continuous 9-0 sutures on the back wall first, followed by the same technique on the front wall ( $D$ and $E$ ). Note the size discrepancy between the varicose vein graft and the $M_{2}$ recipient. The graft was tunneled and connected to the external carotid artery with an end-to-end anastomosis using a double-armed Prolene suture. There was good pulsation in the vein graft $(\mathbf{F})$. The aneurysm had lenticulostriate arteries originating from its walls, and therefore only a proximal occlusion was performed using a permanent clip placement on the $\mathrm{M}_{1}$ segment just as it entered into the aneurysm (G). Doppler flow studies confirmed good perfusion in the distal vessels and in the bypass graft with no changes in the motor evoked or somatosensory evoked potential neurophysiological monitoring. Catheter angiography on postoperative day 1 showed early occlusion of the EC-IC high-flow bypass (left ICA angiogram, anteroposterior [H] and lateral [I] views). The patient experienced an MCA stroke $(\mathrm{J})$ with aphasia and right-sided hemiparesis, as seen on her axial CT scan. This case demonstrates an unexpected bypass occlusion resulting from venous varicosities in the graft and significant caliber mismatch between donor and recipient.

have the opportunity to mature have a high likelihood of remaining patent long term. In experienced hands, cerebral revascularization is a durable treatment option with high patency rates.

\section{References}

1. Abla AA, Lawton MT: Anterior cerebral artery bypass for complex aneurysms: an experience with intracranial-intracranial reconstruction and review of bypass options. J Neurosurg 120:1364-1377, 2014

2. Amin-Hanjani S, Butler WE, Ogilvy CS, Carter BS, Barker FG II: Extracranial-intracranial bypass in the treatment of occlusive cerebrovascular disease and intracranial aneurysms in the United States between 1992 and 2001: a populationbased study. J Neurosurg 103:794-804, 2005

3. Amin-Hanjani S, Du X, Mlinarevich N, Meglio G, Zhao M, Charbel FT: The cut flow index: an intraoperative predictor of the success of extracranial-intracranial bypass for occlusive cerebrovascular disease. Neurosurgery 56 (1 Suppl):75-85, 2005

4. Becske T, Brinjikji W, Potts MB, Kallmes DF, Shapiro M, Moran CJ, et al: Long-term clinical and angiographic outcomes following Pipeline Embolization Device treatment of complex internal carotid artery aneurysms: five-year results of the Pipeline for Uncoilable or Failed Aneurysms trial. Neurosurgery 80:40-48, 2017 
5. Desai ND, Cohen EA, Naylor CD, Fremes SE: A randomized comparison of radial-artery and saphenous-vein coronary bypass grafts. N Engl J Med 351:2302-2309, 2004

6. EC/IC Bypass Study Group: Failure of extracranial-intracranial arterial bypass to reduce the risk of ischemic stroke. Results of an international randomized trial. N Engl J Med 313:1191-1200, 1985

7. Grubb RL Jr, Derdeyn CP, Fritsch SM, Carpenter DA, Yundt $\mathrm{KD}$, Videen TO, et al: Importance of hemodynamic factors in the prognosis of symptomatic carotid occlusion. JAMA 280:1055-1060, 1998

8. Hopkins LN, Budny JL, Spetzler RF: Revascularization of the rostral brain stem. Neurosurgery 10:364-369, 1982

9. Kalani MYS, Zabramski JM, Hu YC, Spetzler RF: Extracranial-intracranial bypass and vessel occlusion for the treatment of unclippable giant middle cerebral artery aneurysms. Neurosurgery 72:428-436, 2013

10. Lawton MT, Spetzler RF: Surgical management of giant intracranial aneurysms: experience with 171 patients. Clin Neurosurg 42:245-266, 1995

11. Martin NA, Kureshi I, Coiteiro D: Bypass techniques for the treatment of intracranial aneurysms. Operative Tech Neurosurg 3:255-270, 2000

12. Mery FJ, Amin-Hanjani S, Charbel FT: Cerebral revascularization using cadaveric vein grafts. Surg Neurol 72:362-368, 2009

13. Morgan MK, Ferch RD, Little NS, Harrington TJ: Bypass to the intracranial internal carotid artery. J Clin Neurosci 9:418-424, 2002

14. Quiñones-Hinojosa A, Du R, Lawton MT: Revascularization with saphenous vein bypasses for complex intracranial aneurysms. Skull Base 15:119-132, 2005

15. Quiñones-Hinojosa A, Lawton MT: In situ bypass in the management of complex intracranial aneurysms: technique application in 13 patients. Neurosurgery 62 (6 Suppl 3):1442-1449, 2008

16. Regli L, Piepgras DG, Hansen KK: Late patency of long saphenous vein bypass grafts to the anterior and posterior cerebral circulation. J Neurosurg 83:806-811, 1995

17. Rodríguez-Hernández A, Josephson SA, Langer D, Lawton MT: Bypass for the prevention of ischemic stroke. World Neurosurg 76 (6 Suppl):S72-S79, 2011
18. Sanai N, Zador Z, Lawton MT: Bypass surgery for complex brain aneurysms: an assessment of intracranial-intracranial bypass. Neurosurgery 65:670-683, 2009

19. Sekhar LN, Kalavakonda C: Cerebral revascularization for aneurysms and tumors. Neurosurgery 50:321-331, 2002

20. Sia SF, Morgan MK: High flow extracranial-to-intracranial brain bypass surgery. J Clin Neurosci 20:1-5, 2013

21. Surdell DL, Hage ZA, Eddleman CS, Gupta DK, Bendok BR, Batjer HH: Revascularization for complex intracranial aneurysms. Neurosurg Focus 24(2):E21, 2008

22. Tayebi Meybodi A, Huang W, Benet A, Kola O, Lawton MT: Bypass surgery for complex middle cerebral artery aneurysms: an algorithmic approach to revascularization. J Neurosurg 127:463-479, 2017

23. Taylor CL, Kopitnik TA Jr, Samson DS, Purdy PD: Treatment and outcome in 30 patients with posterior cerebral artery aneurysms. J Neurosurg 99:15-22, 2003

\section{Disclosures}

The authors report no conflict of interest concerning the materials or methods used in this study or the findings specified in this paper.

\section{Author Contributions}

Conception and design: all authors. Acquisition of data: all authors. Analysis and interpretation of data: Yoon, Burkhardt. Drafting the article: Yoon, Burkhardt. Critically revising the article: all authors. Reviewed submitted version of manuscript: all authors. Approved the final version of the manuscript on behalf of all authors: Lawton. Statistical analysis: Yoon. Administrative/ technical/material support: all authors. Study supervision: all authors.

\section{Correspondence}

Michael T. Lawton: Barrow Neurological Institute, Phoenix, AZ. michael.lawton@barrowbrainandspine.com. 